Research Paper

\title{
A predictive model of offspring congenital heart disease based on maternal risk factors during pregnancy: a hospital based case-control study in Nanchong City
}

\author{
Yun Liang${ }^{1 \#, ~ X i a o q i n ~} \mathrm{Li}^{2 \#}$, Xingsheng $\mathrm{Hu}^{3}$, Bing Wen ${ }^{4}$, Liang Wang${ }^{1}$, Cheng Wang ${ }^{1 凶}$ \\ 1. Department of Pediatric Surgery, Affiliated Hospital of North Sichuan Medical College, Nanchong, 637000, P.R. China; The first affiliated Hospital of Jinan \\ University, Guangzhou, 510632, P.R. China. \\ 2. Department of Nursing, Affiliated Hospital of North Sichuan Medical College, Nanchong, 637000, P.R. China. \\ 3. Department of Cardiology, Nanchong Central Hospital, Nanchong, 637000, P.R. China; Department of Oncology, the second Xiangya Hospital of Central \\ South University Changsha, Yuelu District, 410011, P.R. China (Current Address). \\ 4. Department of Cardiothoracic Surgery, Nanchong Central Hospital, Nanchong, 637000, P.R. China. \\ \#These authors contributed equally to this work.
}

$\square$ Corresponding author: Cheng Wang, Department of Pediatric Surgery, Affiliated Hospital of North Sichuan Medical College, Nanchong, 637000, P.R. China. TEL: +(86)18227398290; E-mail: 361889874@qq.com.

(C) The author(s). This is an open access article distributed under the terms of the Creative Commons Attribution License (https://creativecommons.org/licenses/by/4.0/). See http://ivyspring.com/terms for full terms and conditions.

Received: 2020.05.15; Accepted: 2020.10.07; Published: 2020.10.22

\begin{abstract}
Objective: Based on epidemiological field data, this study was to develop a prediction model which can be used as a preliminary screening tool to identify pregnant women who were at high risk of offspring congenital heart disease (CHD) in Nanchong City, and be beneficial in guiding prenatal management and prevention.

Methods: A total of 367 children with CHD and 367 children without congenital malformations aged 0 to 14 years old were recruited from the Affiliated Hospital of North Sichuan Medical College and Nanchong Central Hospital between March 2016 and November 2018. Using the SPSS 22.0 case-control matching module, the controls were matched to the cases at a rate of $1: 1$, according to the same gestational age of child (premature delivery or full-term), the maternal age of pregnancy (less than 1 year). 327 matched case-control pairs were analyzed by SPSS 22 . Univariate and multivariate analysis were performed to find the important maternal influencing factors of offspring CHD. A logistic regression disease prediction model was constructed as the final predictors, and Hosmer-Lemeshow goodness of fit test and receiver operating characteristic (ROC) curve were used to evaluate the model.

Results: 654 subjects ( 327 cases and 327 controls) were matched. The 25 variables were analysed. The logistic regression model established in this study was as follows: Logit $(P)=-2.871+(0.686 \times$ respiratory infections $)+(1.176 \times$ water pollution $)+(1.019 \times$ adverse emotions during pregnancy $)-(0.617 \times$ nutrition supplementation). The Hosmer-Lemeshow chi-square value was $7.208(\mathrm{df}=6)$, with a nonsignificant $p$ value of 0.302 , which indicates that the model was well-fitted. The calibration plot showed good agreement between the bias-corrected prediction and the ideal reference line. Area under the ROC curve was $0.72(95 \% \mathrm{Cl}$ : $0.681 \sim 0.759)$, which means that the predictive power of the model set fitted the data.

Conclusion: In Nanchong city, more attention should be paid to mother who had a history of respiratory infections, exposure to polluted water, adverse emotions during pregnancy and nutritional deficiency. The risk model might be an effective tool for predicting of the risk of CHD in offspring by maternal experience during pregnancy, which can be used for clinical practise in Nanchong area.
\end{abstract}

Key words: congenital heart disease; risk factors; case-control matching; risk model

\section{Introduction}

Congenital heart disease (CHD) is the most common type of structural congenital malformation and the primary non-infectious cause of death in children: the estimated worldwide prevalence of CHD is about 4-10 in 1,000 live births or 19 in 1,000 live births if potentially serious cases of bicuspid aortic valve are included [1]. In China, the prevalence is 7 to 8 per 1000 live births in high-prevalence areas, which 
represent over 100000 new cases of CHD per year [2]. Several studies have demonstrated an association between environmental risk factors and fetus CHD, and the maternal environment in which a fetus develops has a profound effect on its developmental trajectory, impacting fetal cardiac structure development [3]. Substantial epidemiological evidence associates the sustained presence of adverse healthy lifestyle factors with increased risk of CHD mortality [4]. However, few studies have been done to predict the risk of individual congenital malformations, including CHD [5].

Nanchong, which lies in the northeastern of the Sichuan Basin, is not just a populous city in China, but also an agriculture-oriented developing city [6]. With the resident relocation, urbanization and economic development, pollutants from industrial and domestic wastewaters and agricultural runoffs had exceptionally affected the ecological environment in the Nanchong region [7]. Because of the need of urbanization construction, migrant workers from impoverished rural areas moved to flourishing cities for seeking better job opportunities and pursuing dreams of a better life [8]. These migrant workers, the young in particular, faced many challenges, such as economic pressure, work load, family separation, discrepancies between expectations and reality, and acculturative stress [9]. In order to save money, these people didn't wish to go to the hospital for health examination regularly, and they did not pay enough attention to the health of their offspring [10].

Previously, by using univariate and multivariate methods, we explored the possible parental nonhereditary exposure factors relevant to the occurrence of CHD in the northeastern Sichuan area and evaluated the relative importance of each risk factor [11]. However, we didn't develop an effective CHD prediction model built on comprehensive epidemiological data.

The aim of this study was to establish a prediction model which can be used as a preliminary screening tool to identify pregnant women who were at high risk of offspring CHD in Nanchong City, and be beneficial in guiding prenatal management and prevention.

\section{Materials and methods}

\section{Subjects}

In this hospital-based case-control study, subjects were recruited in two tertiary hospitals from the Affiliated Hospital of North Sichuan Medical College and Nanchong Central Hospital in Nanchong between March 2016 and November 2018. Mothers who gave birth to $\mathrm{CHD}$ infants were involved as cases. CHD was diagnosed by echocardiography. The control group consisted of the mothers whose children were undergoing physical disease treatment (for example, upper respiratory tract infection) in the same period. The exclusion criterions were: chromosome abnormality (for example, Downs syndrome) and other inherited familial diseases; refusal or inability to participate in the survey because of mental symptoms, thinking, or memory disorders.

In this study, to diminish potential risk of bias as far as possible and ensure the statistical power needed to perceive an important predictor, we carried out a case-control study with 1:1 frequency matching.

Informed consent was obtained from all individuals before the interview. The ethical approval of this project was authorized by the Affiliated Hospital of North Sichuan Medical College Ethics Committee [No. 2015ER(A)030]. All the procedures in this study conformed to the Declaration of Helsinki.

\section{Data collection}

All subjects were interviewed face-to-face by well-trained cardiologist and cardiac surgeon and called upon to fill in a questionnaire. The questionnaire included: sociodemographic characteristics, pregnancy history, family history, environmental risk factors, and lifestyle behaviour during pregnancy. The questionnaire was designed by the experts from our research team and modified based on research literature reported by other scholars.

\section{Measurements of risk factors}

\section{Sociodemographic characteristics}

Ethnicity was classified into 2 categories: Han and minorities (minorities were the other 55 ethnicities in China except Han) [12]. Residence was divided into downtown and rural area [13]. Education level was classified into 3 categories: primary school and below; middle school; college and above [2]. Body Mass Index (BMI) was thin ( $\leq 18.4)$, normal (18.5-23.9), overweight (24.0-27.9) and obese $(\geq 28.0)$ [14].

\section{Pregnancy history}

Maternal pregnancy history consisted of history of abnormal reproduction (stillbirth, spontaneous abortion, or birth defect) [2], respiratory infections (for example, pneumonia pharyngitis, influenza or "colds") [15], and medication history (more than 1 day of taking any drug that was used to treat a disease) [16].

\section{Family history}

Family history of CHD was defined as 1 or more first relatives of a CHD patient [15]. 


\section{Environmental risk factors}

Information about exposure to environmental risk factors was collected using the questions with the answer "yes or no". The exposure time of maternal risks was defined as from " 6 months before conception" to "the first trimester of pregnancy" daily. Information about exposure to environmental risk factors included electric radiation (daily contact with mobile phones, microwave ovens, induction cookers, and computers for more than 30 minutes), heavy metals, pesticides (insecticides, herbicides, rodenticide, etc.), organic poisons (lead, mercury, cadmium, benzene, paint, hair dye and other recognized harmful chemical agents), noise (working or living in a noisy environment that causes maternal discomfort), air pollution(referred to the existence of exhaust gas near the plant, a distance from the main traffic road of less than 50 mile or work in the coal-fired power plant), air pollution (the air quality was determined by the local environmental protection department to be at the pollution level), and water pollution (defined as the pollution of drinking water or irrigation water for crops near the factory where the waste water was discharged or recognized by the local environmental protection department) [17].

\section{Lifestyle behaviours}

Maternal lifestyle behaviour was summarized from the same periods as environmental risk factors. Smoking was defined as smoking any cigarette during pregnancy [18]. Alcohol drinking was defined as drinking any liquor, including beer, wine, and white spirits [2]. Addictive drug taking was defined as taking any drugs, including heroin, cannabis, morphine, cocaine and ketamine [19]. Sleep disorder referred to difficulty in falling asleep, light sleep, ease to arousal or waking up early [20]. Adverse emotions during pregnancy referred to bad mood at least once a month, such as tension, injury, anxiety and depression, etc. [21].

\section{Statistical analysis}

Basically there are four data analysis steps. In the first stage, using the SPSS 22.0 case-control matching module, the controls were matched to the cases at a rate of 1:1, according to the same gestational age of child (premature delivery or full-term), the maternal age of pregnancy (less than 1 year). In the second stage, univariate and multivariate analysis were performed to find the important maternal influencing factors of offspring CHD. In the third stage, a logistic regression disease prediction model was constructed as the final predictors. Finally, the predictive ability of the model was evaluated by receiver to operating characteristic curve (ROC) and Hosmer-Lemeshow test.

\section{Results}

Initially, 734 subjects ( 367 cases and 367 controls) were enrolled. The difference between the gestational age of child and maternal gestational age may affect the duration of the foetus under the influence of nongenetic exposure factors, and were treated as potential confounders. We did a matched case-control study to identify risk factors. Finally, 654 subjects (327 cases and 327 controls) were matched (Tables 1 \& 2).

Table 1. Case-Control Matching Statistics

\begin{tabular}{ll}
\hline Match Type & Count \\
\hline Exact Matches & 93 \\
Fuzzy Matches & 234 \\
Unmatched Including Missing Keys & 40 \\
Unmatched With Valid Keys & 40 \\
Sampling & Without Replacement \\
Log File & None \\
Maximize Matching Performance & Yes \\
\hline
\end{tabular}

Table 2. Case-Control Match Tolerances

\begin{tabular}{llll}
\hline Match Variables & Value & $\begin{array}{l}\text { Fuzzy Match } \\
\text { Attempts }\end{array}$ & $\begin{array}{l}\text { Incremental Rejection } \\
\text { Percentage }\end{array}$ \\
\hline Exact (All Variables) & & 466.3000 & 98.006 \\
Gestational Age & 1.000 & 4570.000 & 90.263 \\
Maternal Age of Pregnancy & 0.000 & 445.000 & 47.416 \\
\hline
\end{tabular}

The 25 variables listed in Table 3 were analysed by univariate logistic regression. Table 3 showed the 17 significant predictors of CHD risk selected by univariate logistic regression. The following 3 factors were significantly associated with the increased risk of CHD by multivariate logistic regression analyses (Table 4): respiratory infections $(B=0.686, O R=1.986$, 95\% CI: 1.336 2.952), exposure to polluted water $(\mathrm{B}=$ 1.176, OR $=3.242,95 \%$ CI: 1.872 5.613), adverse emotions during pregnancy $(\mathrm{B}=1.019$, $\mathrm{OR}=2.769$, 95\% CI: 2.005 3.824). The occurrence of CHD was inversely related to nutrition supplementation (B = $-0.617, \mathrm{OR}=0.540,95 \% \mathrm{CI}: 0.381 \sim 0.765)$ as a protective factors (Table 4). The logistic regression model established in this study was as follows: $\operatorname{Logit}(\mathrm{P})=-2.871+(0.686 \times$ respiratory infections $)+(1.176$ $\times$ water pollution $)+(1.019 \times$ adverse emotions during pregnancy) - (0.617×nutrition supplementation). The Hosmer-Lemeshow chi-square value was 7.208 (df = 6), with a nonsignificant $p$ value of 0.302 , which indicates that the model was well-fitted. The calibration plot showed good agreement between the bias-corrected prediction and the ideal reference line (Figure 1). Figure 2 shows the Receiver Operating Curve (ROC Curve). Area under the ROC curve was 
0.72 (95\% CI: 0.681 0.759), which means that the predictive power of the model set fitted the data.

Table 3. Univariate analysis of research factors among cases and controls

\begin{tabular}{|c|c|c|c|c|c|c|}
\hline \multirow[t]{2}{*}{ Research factors } & \multicolumn{2}{|c|}{ Controls $(\mathrm{N}=327)$} & \multicolumn{2}{|c|}{ Cases $(\mathrm{N}=327)$} & \multirow[t]{2}{*}{$X^{2}$ value } & \multirow[t]{2}{*}{$P$ value } \\
\hline & $\mathrm{N}$ & $\%$ & $\mathrm{~N}$ & $\%$ & & \\
\hline \multicolumn{5}{|l|}{ Permanent residence } & 0.646 & 0.421 \\
\hline Rural area & 80 & 75.5 & 89 & 27.2 & & \\
\hline Downtown & 247 & 24.5 & 238 & 72.8 & & \\
\hline \multicolumn{5}{|l|}{ Ethnicity } & 0.358 & 0.549 \\
\hline Han & 262 & 80.1 & 268 & 82.0 & & \\
\hline Minorities & 65 & 19.9 & 59 & 18.0 & & \\
\hline \multicolumn{5}{|l|}{ Education level* } & 9.100 & 0.011 \\
\hline Primary school and below & 45 & 13.8 & 44 & 13.5 & & \\
\hline Middle school & 76 & 23.2 & 110 & 33.6 & & \\
\hline College and above & 206 & 63.0 & 173 & 52.9 & & \\
\hline \multicolumn{5}{|c|}{ History of abnormal reproduction* } & 8.203 & 0.004 \\
\hline None & 299 & 91.4 & 275 & 84.1 & & \\
\hline Yes & 28 & 8.6 & 52 & 15.9 & & \\
\hline \multicolumn{5}{|c|}{ Family history of congenital heart disease* } & 4.098 & 0.043 \\
\hline None & 290 & 88.7 & 272 & 83.2 & & \\
\hline Yes & 37 & 11.3 & 55 & 16.8 & & \\
\hline BMI & & & & & 4.310 & 0.230 \\
\hline Thin $(\leq 18.4)$ & $36 a$ & 11.0 & $45 a$ & 13.8 & & \\
\hline Normal (18.5-23.9) & $192 \mathrm{a}$ & 58.7 & $171 \mathrm{a}$ & 52.3 & & \\
\hline Overweight (24.0-27.9) & $90 \mathrm{a}$ & 27.5 & $95 \mathrm{a}$ & 29.1 & & \\
\hline Obese $(\geq 28.0)$ & $9 a$ & 2.8 & $16 a$ & 4.9 & & \\
\hline \multicolumn{5}{|l|}{ Respiratory infections* } & 10.910 & 0.001 \\
\hline None & 267 & 81.7 & 231 & 70.6 & & \\
\hline Yes & 60 & 18.3 & 96 & 29.4 & & \\
\hline \multicolumn{5}{|l|}{$\begin{array}{l}\text { Infection of female } \\
\text { reproductive system* }\end{array}$} & 8.724 & 0.003 \\
\hline None & 318 & 97.2 & 301 & 92.0 & & \\
\hline Yes & 9 & 2.8 & 26 & 8.0 & & \\
\hline \multicolumn{5}{|l|}{ Medication history* } & 8.402 & 0.004 \\
\hline None & 262 & 80.1 & 230 & 70.3 & & \\
\hline Yes & 65 & 19.9 & 97 & 29.7 & & \\
\hline Electrical radiation* & & & & & 7.618 & 0.022 \\
\hline None & 104 & 31.8 & 85 & 27.8 & & \\
\hline Yes & 223 & 68.2 & 247 & 72.2 & & \\
\hline Noise & & & & & 2.810 & 0.094 \\
\hline None & 300 & 91.7 & 287 & 87.8 & & \\
\hline Yes & 27 & 8.3 & 40 & 12.2 & & \\
\hline Heavy metals* & & & & & 6.146 & 0.013 \\
\hline None & 310 & 94.8 & 288 & 89.6 & & \\
\hline Yes & 17 & 5.2 & 34 & 10.4 & & \\
\hline Pesticides* & & & & & 7.181 & 0.007 \\
\hline None & 318 & 97.2 & 303 & 92.7 & & \\
\hline Yes & 9 & 2.8 & 24 & 7.3 & & \\
\hline Organic solvents & & & & & 2.353 & 0.125 \\
\hline None & 285 & 87.2 & 271 & 82.9 & & \\
\hline Yes & 42 & 12.8 & 56 & 17.1 & & \\
\hline Air pollution & & & & & 3.570 & 0.059 \\
\hline None & 274 & 83.8 & 255 & 78.0 & & \\
\hline Yes & 53 & 16.2 & 72 & 22.0 & & \\
\hline Water pollution* & & & & & 22.731 & 0.000 \\
\hline None & 305 & 93.3 & 264 & 80.7 & & \\
\hline Yes & 22 & 6.7 & 63 & 19.3 & & \\
\hline Active smoking* & & & & & 6.498 & 0.039 \\
\hline None & 294 & 89.9 & 278 & 85.0 & & \\
\hline Yes & 33 & 10.1 & 49 & 15.0 & & \\
\hline Passive smoking* & & & & & 11.779 & 0.001 \\
\hline None & 275 & 84.1 & 239 & 73.1 & & \\
\hline Yes & 52 & 15.9 & 88 & 26.9 & & \\
\hline Drinking* & & & & & 11.422 & 0.003 \\
\hline None & 300 & 91.7 & 272 & 83.2 & & \\
\hline Yes & 27 & 8.3 & 55 & 16.8 & & \\
\hline Addictive drugs & & & & & 0.914 & 0.339 \\
\hline None & 320 & 97.9 & 316 & 96.6 & & \\
\hline Yes & 7 & 2.1 & 11 & 3.4 & & \\
\hline Sleep disorder* & & & & & 4.407 & 0.036 \\
\hline
\end{tabular}

\begin{tabular}{|c|c|c|c|c|c|c|}
\hline \multirow{2}{*}{ Research factors } & \multicolumn{2}{|c|}{ Controls $(\mathrm{N}=327)$} & \multicolumn{2}{|c|}{ Cases $(\mathrm{N}=327)$} & \multirow[t]{2}{*}{$X^{2}$ value } & \multirow[t]{2}{*}{$P$ value } \\
\hline & $\mathrm{N}$ & $\%$ & $\mathrm{~N}$ & $\%$ & & \\
\hline None & 310 & 94.8 & 293 & 90.5 & & \\
\hline Yes & 17 & 5.2 & 29 & 9.5 & & \\
\hline \multicolumn{5}{|c|}{ Adverse emotions during pregnancy* } & 56.652 & 0.000 \\
\hline None & 245 & 74.9 & 156 & 48.4 & & \\
\hline Yes & 82 & 25.1 & 171 & 52.3 & & \\
\hline \multicolumn{5}{|c|}{ Nutrition supplementation ${ }^{*}$} & 14.371 & 0.000 \\
\hline None & 180 & 55.0 & 227 & 69.4 & & \\
\hline Yes & 147 & 45.0 & 100 & 30.6 & & \\
\hline \multicolumn{5}{|c|}{ Periodic prenatal examination* } & 4.155 & 0.042 \\
\hline None & 139 & 42.5 & 165 & 50.5 & & \\
\hline Yes & 188 & 57.5 & 162 & 49.5 & & \\
\hline
\end{tabular}

Table 4. Results of multivariate conditional logistic analysis

\begin{tabular}{|c|c|c|c|c|c|}
\hline Factor & B & S.E & $P$ value & OR & $95 \%$ CI \\
\hline Respiratory infections & 0.686 & 0.202 & 0.001 & 1.986 & $1.336 \sim 2.952$ \\
\hline Exposure to polluted water & 1.176 & 0.280 & 0.000 & 3.242 & $1.872 \sim 5.613$ \\
\hline $\begin{array}{l}\text { Adverse emotions during } \\
\text { pregnancy }\end{array}$ & 1.019 & 0.165 & 0.000 & 2.769 & $2.005 \sim 3.824$ \\
\hline Nutrition supplementation & -0.617 & 0.182 & 0.001 & 0.540 & $0.381 \sim 0.765$ \\
\hline Constant & -2.871 & 0.556 & 0.000 & 0.057 & \\
\hline
\end{tabular}

Note: B: Beta; S.E: standard error; OR: odds ratio; $95 \%$ CI: $95 \%$ confidence interval.

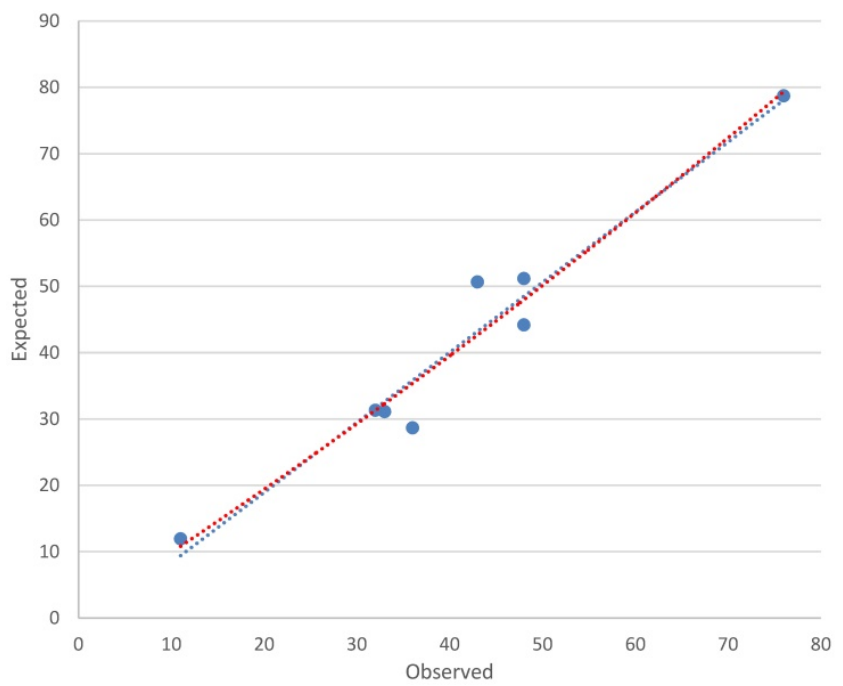

Figure 1. Scatter Diagram of Calibration.

\section{Discussion}

The outcome of this study has shed more light on risk factors of CHD in offspring caused by maternal non-genetic exposure. This study has attempted to control for the effects of potential confounders by comprising many factors into the analyses without over-modelling. Effective nutrition supplementation was found to have an inverse relationship with offspring CHD. Inadequate maternal nutrition was a recognized risk factor in child development, which had been confirmed by many scholars [22]. Prior studies showed that multivitamin or folic acid use before or during early pregnancy may 
antagonistically affect the biological process of vascular disruption and/or apoptosis, and seems to rescue apoptotic cells of folate deficient [23]. Miki emphasized the significant interactions between fatty acid metabolism and further underscored the importance of proper maternal nutrition during gestational age for proper organ development and function among all vertebrate species [24]. The results of this study emphasized again how important it is to get effective nutrition supplementation for mother.

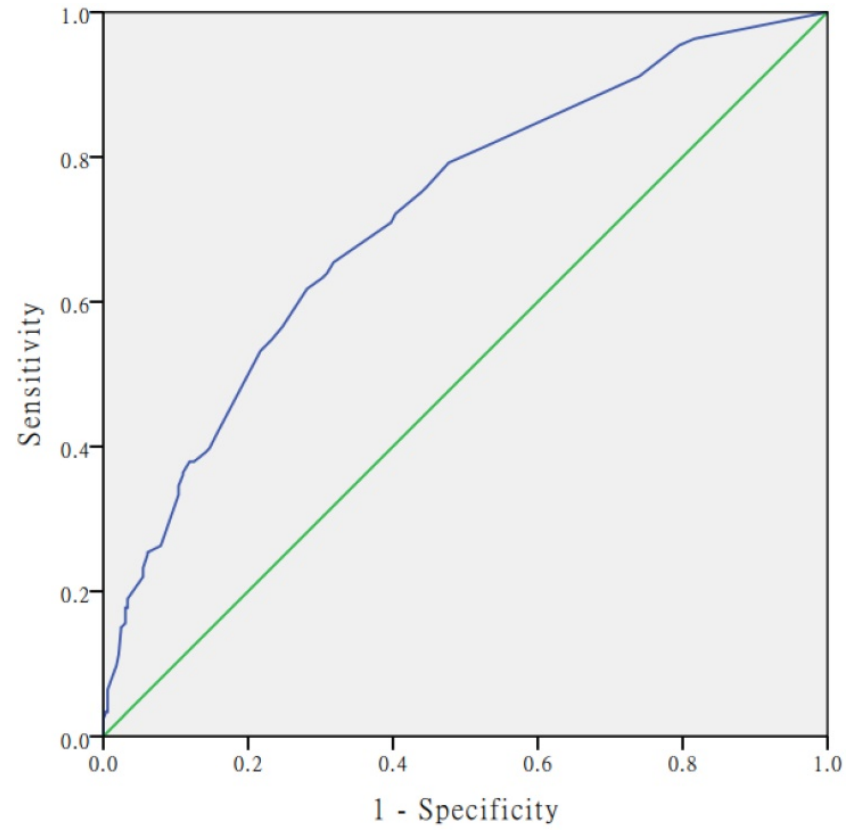

Figure 2. The receiver operating characteristic (ROC) curve of the multivariate logistic regression model.

In our study, maternal exposure to polluted water during pregnancy was risk factor for offspring CHD. With the rapid development of economy, water pollution had grown up to be a serious problem in China [25]. At least 70 percent of lakes and rivers in China were polluted, with more than half of the water sources were unsuitable for human contact [26]. Around $60 \%$ of China's underground water had inferior water quality and over $80 \%$ of petrochemical and chemical facilities were situated in easy reach of rivers and water tables [27]. To date, more than 350 million people in the country had no access to safe drinking water, despite recent progress about improving the water quality of Chinese natural water sources [28]. The reason for the above phenomena can be attributed to expanding construction of cities, overused fertilizers and toxic chemicals and emissions from industries [29]. Kim J et al reported that cardiac malformations were positively correlated with pollutants in drinking water, such as trichloroethylene, tetrachloroethylene, dichloromethane, and benzene [30]. Meanwhile, it was confirmed that the risk of ventricular septal defect (VSD) can be increased by trichloroacetic acid, trihalomethane and dichloroethylene in drinking water [2,31]. In Nanchong, there were two main sources of nitrate that pollute groundwater [32]. One was the discharge of sewage and waste water from the surface, such as sewage from urban septic tanks, sewage leaked from sewage pipes, or garbage piles leached by rainwater [11]. In the process of discharge, the polluted water from this source would seep into the river, thus polluting the groundwater resources [32]. Secondly, agricultural non-point sources pollute the water source, which leaded to the over standard of nitrate and heavy metals in groundwater resources [32,33]. It was usually necessary to apply nitrogen fertilizer in the farmland, so nitrogen will seep into the farmland; the content will be $12.5 \%-45 \%$ nitrogen fertilizer [34]. When crops such as vegetables were irrigated with wastewater contaminated with heavy metals, dietary intake would become the main route of heavy metal exposure [33]. Over the past few years, ecological environment of Nanchong city had been subjected to heavy metal accumulation as a result of rapid economic development, urbanization and industrialization [35,36]. As mentioned before, environmental exposure factors were related to environmental pollution. Inappropriate urbanization and extensive economic growth had significant influences on the regional environment in the context of rapid urbanization in China [37]. Thus, it can be considered as a warning that it is undesirable to develop the economy at the expense of the environment.

Our findings support those of other studies that maternal adverse emotions, a common morbidity during pregnancy, can lead to poor birth outcomes [38]. Xiaoqiang, $Q$ et al reported that psychological trauma or tension, stimulating the sympathetic adrenomedullin system and pituitary adrenocortical system, will cause a series of physiological changes and increase the risk of teratogenesis [39]. Shaw, C et al reported that stressful events during pregnancy will lead to cardiac malformations of the outflow tract, neural tube malformations and cleft lip [40]. Therefore, to maintain a positive mood may not only be beneficial for reproductive health but also for maternal health.

Evidence from the previous literature shows that prenatal maternal influenza during 3 months before pregnancy through the third month of pregnancy may be associated with right-sided obstructive lesions in all infants and with atrioventricular septal defects in infants with Down syndrome [41]. Another study indicated that a febrile illness around the time of conception or in early pregnancy was associated with 
an approximately two-fold increased risk for major heart defects [42]. The new data that reported by Tian Xia revealed a stronger link between air pollution exposure and the development of respiratory diseases, including acute respiratory infections, and lung cancer, as well as cardiovascular diseases [43]. Nanchong city lies in the northeastern of the Sichuan Basin, which is not conducive to the diffusion of air pollutants, dominatingly leading to the highest particulate matter concentrations [28]. Therefore, controlling air pollution may be an effective measure to reduce respiratory tract infection.

\section{Study limitations}

The limitations of our study need to be addressed: (1) elf-report information would bring recall bias. (2) Hospital-based case-control studies may bring about selection bias. (3) Another unavoidable problem is that some research volunteers couldn't accurately confirm exposures status, and categorize the duration and correlation total; the estimates were not particularly imprecise. (4) When different matching criteria are used, the matched case-control statistical results may be different. Future studies and potential analysis should consider these factors.

\section{Conclusion}

In Nanchong city, more attention should be paid to mothers who had a history of respiratory infections, exposure to polluted water, adverse emotions during pregnancy and nutritional deficiency as these mothers may be likely to have a baby suffering from CHD. The risk model might be an effective tool for predicting of the risk of CHD in offspring by maternal experience during pregnancy, which can be used for clinical practise in Nanchong area.

\section{Acknowledgements}

This work was supported by the Primary Health Development Research Center of Sichuan Province funds (grant numbers: SWFZ20-Y-030), Nanchong Municipal School Cooperation Project Funds (grant numbers: 19SXHZ0352) and Sichuan Provincial Health and Family Planning Commission funds (grant numbers: 16PJ126).

\section{Contributions}

Conception and design: Yun Liang; Data analysis and interpretation: Yun Liang and Xingsheng $\mathrm{HU}$; Data collection and management: Liang Wang, Xiaoqin Li, and Bing Wen; Manuscript writing and critical revisions: all authors; Overall responsibility: Cheng Wang and Yun Liang.

\section{Competing Interests}

The authors have declared that no competing interest exists.

\section{References}

1. Oguz MM, Oguz AD, Sanli C, Cevik A. Serum levels of soluble ICAM-1 in children with pulmonary artery hypertension. Texas Hear Inst J [Internet]. 2014;41(2):159-164.

2. Liu S, Liu J, Tang J, Ji J, Chen J, Liu C. Environmental Risk Factors for Congenital Heart Disease in the Shandong Peninsula, China: A Hospital-based Case-Control Study. J Epidemiol. 2009;19(3):122-130.

3. García A, Moreno $\mathrm{K}$, Ronderos M, Sandoval N, Caicedo M, Dennis RI. Differences by Altitude in the Frequency of Congenital Heart Defects in Colombia. Pediatr Cardiol [Internet]. 2016;37(8):1507-1515.

4. Spring B, Moller AC, Colangelo LA, Siddique J, Roehrig M, Daviglus ML, et al. Healthy lifestyle change and subclinical atherosclerosis in young adults: Coronary Artery Risk Development in Young Adults (CARDIA) study. Circulation [Internet]. 2014;130(1):10-17.

5. Zhang W, Spero TL, Nolte CG, Garcia VC, Lin Z, Romitti PA, et al. Projected Changes in Maternal Heat Exposure During Early Pregnancy and the Associated Congenital Heart Defect Burden in the United States. J Am Heart Assoc [Internet]. 2019;8(3):e010995.

6. Xuxi W, Li P, Chunjiang S, Yuxiang M, Xiaolan W. Emergy Analysis and Sustainable Development of Agriculture Ecosystems in Sichuan Province:Analysis Based on the Five Different Economic Regions. Areal Res Dev. 2015;34(5):128-132,166.

7. Jing T, Ziquan Z, Li S. Influence of Urbanization on Ecological Environment in Hilly Areas of Nanchong City of Sichuan Basin. Environ Sci Manag. 2015;40(1):177-179.

8. Yang H, Gao J, Wang T, Yang L, Liu Y, Shen Y, et al. Association between adverse mental health and an unhealthy lifestyle in rural-to-urban migrant workers in Shanghai. J Formos Med Assoc [Internet]. 2017;116(2):90-98.

9. Zhang J, Li X, Fang X, Xiong Q. Discrimination experience and quality of life among rural-to-urban migrants in China: the mediation effect of expectationreality discrepancy. Qual Life Res [Internet]. 2009;18(3):291-300.

10. Bonnet F, Irving K, Terra J-L, Nony P, Berthezène F, Moulin P. Anxiety and depression are associated with unhealthy lifestyle in patients at risk of cardiovascular disease. Atherosclerosis [Internet]. 2005;178(2):339-344.

11. Liang $\mathrm{Y}, \mathrm{Hu} \mathrm{X}, \mathrm{Li} \mathrm{X}$, Wen B, Wang L, Wang C. Parental non-hereditary teratogenic exposure factors on the occurrence of congenital heart disease in the offspring in the northeastern Sichuan, China. Sci Rep [Internet]. 2020;10(1):3905.

12. Nembhard WN, Salemi JL, Ethen MK, Fixler DE, Canfield MA. Mortality among infants with birth defects: Joint effects of size at birth, gestational age, and maternal race/ethnicity. Birth Defects Res Part A Clin Mol Teratol. 2010;88(9):728-736.

13. Rongxin L, Qianjin Z, Yongjian F. Risk factors for congenital heart disease in Chinese population:A meta-analysis. J Third Mil Med Univ. 2011;(12):12651268.

14. Brite J, Laughon S, Troendle J, Mills J. Maternal overweight and obesity and risk of congenital heart defects in offspring. Int J Obes (Lond). 2013;38(6):878-882.

15. Li H, Luo M, Zheng J, Luo J, Zeng R, Feng N, et al. An artificial neural network prediction model of congenital heart disease based on risk factors: A hospitalbased case-control study. Medicine (Baltimore) [Internet]. 2017;96(6):e6090.

16. Frederiksen MC. Consideration for the Use of Therapeutic Drugs During Pregnancy and the Perinatal Period. Princ Gender-Specific Med. 2004;2:869-873

17. Baldacci S, Gorini F, Minichilli F, et al. Review of epidemiological studies on individual and environmental risk factors in the aetiology of congenital heart defects. Epidemiologia e Prevenzione. 2016;40(3):185-196.

18. Jingmei $\mathrm{D}$. Risk factors and prenatal diagnostic methods for congenital heart disease: A meta-analysis. Huazhong University of Science and Technology; 2013; p:106

19. Jifang L, Zhizhe L. Drugs and deformities. GANSU Sci Technol. 2008;24(32):153-154.

20. Javaheri S, Redline S. Insomnia and risk of cardiovascular disease. Chest. 2017;152(2):435-444.

21. Conde A, Figueiredo B, Tendais I, Teixeira C, Costa R, Pacheco A, et al. Mother's anxiety and depression and associated risk factors during early pregnancy: effects on fetal growth and activity at 20-22 weeks of gestation. J Psychosom Obstet Gynaecol. 2010;31(2):70.

22. Alderman $\mathrm{H}$, Hawkesworth S, Lundberg M, Tasneem A, Mark H, Moore S. Supplemental feeding during pregnancy compared with maternal supplementation during lactation does not affect schooling and cognitive development through late adolescence. Am J Clin Nutr. 2013;16:99.

23. Qin C, Li Y, Wang D, Shi Z, Yao R, Wang D, et al. Maternal factors and preoperative nutrition in children with mild cases of congenital heart disease. Japan J Nurs Sci Jjns. 2018;16(1):37.

24. Igarashi M, Santos R, Cohen-Cory S. Impact of Maternal n-3 Polyunsaturated Fatty Acid Deficiency on Dendritic Arbor Morphology and Connectivity of 
Developing Xenopus laevis Central Neurons In vivo. J Neurosci. 2015;35:60796092.

25. Xuewei L, Wang Yuhui, Li Sha. The root cause of groundwater pollution and its treatment analysis. Inn Mong Environ Sci. 2018;30(12):57-58.

26. Stalley P. Mind the Gap: The Role of Foreign-Invested Firms in Narrowing the Implementation Gap in China's Environmental Governance BT - Chinese Environmental Governance: Dynamics, Challenges, and Prospects in a Changing Society. In: Ren B, Shou H, editors. New York: Palgrave Macmillan US. 2013; p:141-158.

27. Xiyue, Jia, David, O'Connor, Deyi, Hou, et al. Groundwater depletion and contamination: Spatial distribution of groundwater resources sustainability in China. Sci Total Environ. 2019; p:551-562.

28. Tao X. Air and Water Pollution Evaluation Under Present Condition and Its Control Measures in Nanchong City. Shandong Chem Ind. 2018;47(11):193-195.

29. Wu J, Deng Y, Huang J, Morck R, Yeung B. Incentives and Outcomes: China's Environmental Policy. Capital Soc. 2014;9:1-41.

30. Kim J, Swartz M, Langlois P, Romitti P, Weyer P, Mitchell L, et al. Estimated Maternal Pesticide Exposure from Drinking Water and Heart Defects in Offspring. Int J Environ Res Public Heal. 2017;14(8):889.

31. Yani L, Zhongmei L, Yunzhu P. Research progress on environmental related risk factors of congenital heart disease. Shandong Med J. 2017;57(8):109-112.

32. Ling-yun Z, Zhen-wei X, Zhao-hui R. Studies on Residues of Organochlorine in Soils in Rural Nanchong. Sichuan Environ. 2012;31(6):9-12.

33. Guo-qin $\mathrm{W}$, Zhen $\mathrm{H}$. Investigation into Heavy Metal( $\mathrm{Pb}, \mathrm{Cd})$ Pollution of Vegetables and Soil in Nanchong Suburb. J Chang Veg. 2010;(2):39-41.

34. Zhang X. Discussion on water environment problem and water pollution control in jialing river basin. Shuili Tiandi. 2015;(1):33-36.

35. Hongxia L, Tongde Z, Zhonglan C. Contents of Heavy Metal in Leaves of Plants and Air Pollution Evaluation in Nanchong Region. J CHINA WEST Norm Univ Sci. 2006;27(4):435-438.

36. Yuchen L, Lilin W, Jun W. Pollution and source analysis of heavy metals in municipal solid waste in Sichuan. Chinese J Environ Eng. 2015;9(12):60106018

37. Yajie Z, Leying W, Feng Z, Xiaoshuang Y. Urbanization Quality Evaluation and Its Influencing Factors of Chengdu-chongqing Urban Agglomeration. Geomatics World. 2019;26(1):48-63.

38. SM O, Kenny L, Khashan A, West H, RMD S, Kearney P. Different insulin types and regimens for pregnant women with pre-existing diabetes. Cochrane Database Syst Rev. 2017; 2(2): CD011880.

39. Xiao-qiang $\mathrm{Q}$ ZHONG Qiu-an, ZENG Xiao-yun, LI Yong-hong, NIE Shao-fa. A case-control study on congenital heart diseases with methylenetetrahydrofolate reductase gene,cystathionine $\beta$-synthase gene,and environmental factors. CHINESE J Epidemiol. 2006;27(3):260-263.

40. Carmichael SL, Shaw GM. Maternal life event stress and congenital anomalies. Epidemiology [Internet]. 2000;11(1):30-35.

41. Oster M, Riehle-Colarusso T, Alverson C, Correa A. Associations Between Maternal Fever and Influenza and Congenital Heart Defects. J Pediatr. 2011;158:990-995.

42. Botto L, Lynberg M, Erickson JD. Congenital Heart Defects, Maternal Febrile Illness, and Multivitamin Use: A Population-Base Study. Epidemiology. 2001:12:485-490

43. Xia T, Zhu Y, Mu L, Zhang Z-F, Liu S. Pulmonary diseases induced by ambient ultrafine and engineered nanoparticles in twenty-first century. Natl Sci Rev [Internet]. 2016;3(4):416-429. 